\title{
Depósitos carbonáticos de Tangará da Serra (MT): uma nova ocorrência de capa carbonática neoproterozóica no sul do Cráton Amazônico
}

\author{
Joelson Lima Soares ${ }^{1} \&$ Afonso César Rodrigues Nogueira ${ }^{2}$
}

\begin{abstract}
Resumo Capas carbonáticas se traduzem num dos mais importantes depósitos relacionados ao final das glaciações globais neoproterozóicas. Na região de Tangará da Serra, margem sul do Cráton Amazônico, foi descrita uma sucessão carbonática neoproterozóica de aproximadamente $20 \mathrm{~m}$ de espessura que inclui o topo da Formação Mirassol d'Oeste e a base da Formação Guia, respectivamente as capas dolomítica e calcária da base do Grupo Araras. A capa dolomítica é composta por dolograisntones peloidais rosados com laminação plano paralela e truncamentos de baixo ângulo, interpretados como registros de uma plataforma rasa a moderadamente profunda. A capa calcária consiste em siltitos maciços e laminados e calcários finos cristalinos com acamamento de megamarcas onduladas, interpretados como depósitos de plataforma mista moderadamente profunda dominada por ondas. Calcários finos cristalinos com laminação ondulada/marcas onduladas e leques de cristais (pseudomorfos de aragonita) intercalados com folhelhos foram interpretados como depósitos de plataforma profunda e supersaturada em $\mathrm{CaCO}_{3}$ Calcários com estruturas de escorregamento (slump), laminações convolutas e falhas sin-sedimentares caracterizam depósitos de talude e diques neptunianos, preenchidos por brechas calcárias, e camadas deformadas isoladas sugerem atividade sísmica durante a sedimentação. A sucessão carbonática de Tangará da Serra estende a ocorrência de capas carbonáticas no sul do Cráton Amazônico e corrobora com a presença de uma extensa plataforma carbonática formada durante a transgressão após a glaciação Puga correlata ao evento Marinoano.
\end{abstract}

Palavras-chave: Capa carbonática, Neoproterozóico, Cráton Amazônico, Fácies sedimentares, glaciação.

\begin{abstract}
Carbonates deposits of Tangará da Serra-MT: a new occurrence of neoproterozoic cap carbonate in southern Amazon Craton. Cap carbonates are exceptional deposits related to the end of Neoproterozoic low-latitude glaciations. In the Tangará da Serra region, south Amazon craton, was described a Neoproterozoic carbonatic succession with approximately $20 \mathrm{~m}$ thick that includes the upper part of the Mirassol d'Oeste Formation and the base of the Guia Formation, respectively the dolomitic and calcareous caps of basal Araras Group. The cap dolomite is composed of pinkish peloidal dolograinstones with planar to low angle truncated laminations interpreted as deposits of a shallow to moderately deep platform. The cap limestone consists in massive to laminated siltstone and megaripple bedded crystalline limestone interpreted as deposits of moderately deep wave dominated mixed platform. Rippled crystalline limestone with crystals fans (pseudomorphosed aragonite) interbedded with shales were interpreted as oversaturated- $\mathrm{CaCO}_{3}$ deep platform deposits. Limestone with slump structures, convolute bedding and sinsedimentary faults characterize deposits of slope and neptunians dykes, filled by calcareous breccias, and isolated deformed limestone beds suggest seismic activity during the sedimentation. The succession of Tangará da Serra extends the occurrence of cap carbonates in the southern Amazon craton and corroborate with the presence of a large carbonate to mixed platform formed during the transgression after the glaciation Puga, correlate to Marinoan event.
\end{abstract}

Keywords: Cap carbonate, Neoproterozoic, Amazon craton, Sedimentary Facies, glaciation.

INTRODUÇÃO O intervalo entre o Neoproterozóico e o Cambriano ( $\sim 550 \mathrm{Ma})$ é atualmente alvo de grande discussão no meio científico devido à ocorrência de importantes mudanças paleoceanográficas evolutivas e climáticas (Kirschvink 1992, Knoll \& Walter 1992, Grotzinger \& Knoll 1995, Hoffman \& Schrag 2002). Glaciações que alcançaram até baixas latitudes do globo que resultaram em importantes mudanças atmosféricas e paleoceanográficas ocorreram pelo menos em duas oportunidades nos últimos 200 Ma do Neoproterozóico, no Esturtiano (750 Ma) e no Marinoano (635 Ma), além da glaciação regional Gaskiers de 580 Ma (Kirschvink 1992, Kennedy 1996, Hoffman \& Schrag 2002, Bowring et al. 2003, Halverson et al. 2005, Fike et al. 2006, Alvarenga et al. 2007). Existem atualmente duas hipóteses relevantes sobre as glaciações globais neopro-

1 - Programa de Pós-Graduação em Geologia Regional e Ambiental, Departamento de Geociências, Universidade Federal do Amazonas, Manaus (AM), Brasil. E-mail: joelsonls@gmail.com

2 - Instituto de Geociências da Universidade Federal do Pará, Belém (PA), Brasil. Bolsista de produtividade do CNPq.

E-mail: anogueira@ufpa.br 
terozóicas: 1) a hipótese da snowball Earth que sugere o total congelamento da superfície da Terra, acompanhado pela paralisação do ciclo hidrológico e eliminação parcial da vida (Hoffman et al. 1998a e b); e 2) a teoria do slushball Earth, baseada em simulações paleoclimáticas, que admite as glaciações de grandes extensões porém com áreas equatoriais livres de gelo e propícias à sustentação da vida (Hyde et al. 2000, Moczydlowska 2008). Os registros destes eventos glaciais são encontrados em regiões cratônicas e faixas móveis de vários continentes sob a forma de depósitos glaciais e carbonáticos contemporâneos (Fairchild \& Hambrey 1984, Santos et al. 2000, James et al. 2001, Nogueira et al. 2003, Trindade et al. 2003, Alvarenga et al. 2004, Font et al. 2006, Nogueira \& Riccomini 2006, Misi et al. 2007, Alvarenga et al. 2008). Os carbonatos têm sido referenciados como capas carbonáticas relacionadas às glaciações de baixas latitudes, caracterizados por dolomitos rosados que sobrepõem diamictitos glaciais sem evidência de hiato, possuem fácies especificas e expressiva excursão negativa de $\delta^{13} \mathrm{C}$ (Narbonne et al. 1994, Kennedy 1996 , Myrow \& Kaufman 1999, Hoffman et al. 1998, Hoffman \& Schrag 2000, Kennedy et al. 2001, Nogueira et al. 2003, 2007, Allen \& Hoffman 2005).

No Brasil os registros anômalos do Neoproterozóico foram pela primeira vez documentados na Plataforma Sul-Americana na margem sul do Cráton Amazônico, nos depósitos da Plataforma Carbonática Araras, com a identificação de uma capa carbonática pós-glaciação Puga (Marinoana) na mina Terconi, região de Mirassol d'Oeste, Estado do Mato Grosso (Nogueira 2003, Nogueira et al. 2003, Trindade et al. 2003, Font et al. 2006, Nogueira et al. 2007). A descoberta de uma nova ocorrência desta unidade na mina de calcário Tangará, em Tangará da Serra, Mato Grosso, possibilitou a continuidade da análise paleoambiental e estratigráfica de capas carbonáticas neoproterozóicas, além de ampliar os registros das condições de snowball/slushball Earth.

A região de Tangará da Serra, Estado do Mato Grosso, situa-se a $140 \mathrm{~km}$ à nordeste da cidade de Mirassol d'Oeste e distante $240 \mathrm{~km}$ a noroeste da capital Cuiabá, encerrada entre as serras de Tapirapuã e dos Parecis (Fig. 1). A região apresenta relevo de topografia plana, sendo as melhores exposições encontradas nas frentes de lavra pertencentes à Mina Calcário Tangará (Fazenda Alvorada) e nas margens do rio Sepotuba, afluente do rio Paraguai (Fig. 1). O presente trabalho tem como objetivo descrever as principais características faciológicas e estratigráficas da capa carbonática recentemente descoberta em Tangará da Serra e tentar correlacioná-la com a capa encontrada em Mirassol d'Oeste.

GEOLOGIA REGIONAL O Grupo Araras aflora descontinuamente na margem sul do Cráton Amazônico e com maior continuidade na porção norte da Faixa de Dobramentos Paraguai, consistindo em uma sucessão predominantemente carbonática com espessura superior a $1200 \mathrm{~m}$ (Fig. 1). As ocorrências desta unidade sobre o cráton, diferentemente daquelas da Faixa Para- guai que são dobradas, são desprovidos de metamorfismo, exibem mergulhos subhorizontais e forma platôs tabulares que conferem um relevo aplainado a região.

Nogueira \& Riccomini (2006) subdividiram formalmente o Grupo Araras em quatro formações, da base para o topo, Mirassol d'Oeste, Guia, Serra do Quilombo e Nobres. A Formação Mirassol d'Oeste, de $15 \mathrm{~m}$ de espessura, consiste em dolomitos finos de coloração rosada, estromatólitos e dolomitos pelóidais, interpretada como plataforma rasa com base sobreposta diretamente ao diamictito da Formação Puga, onde o contato é brusco e lateralmente irregular e ondulado, com deformações plásticas atribuídas a sismicidade induzida por rebound pós-glacial e que representam o registro de uma rápida mudança de condições glaciais para de efeito estufa (Nogueira et al. 2003, Nogueira \& Riccomini 2006). Esta unidade é interpretada como uma capa dolomítica (Nogueira et al. 2003) depositada logo após a glaciação Puga, correlata ao episódio Marinoano, trata-se de um importante marco estratigráfico global por ser à base do período Ediacarano na região. A Formação Guia, com aproximadamente 200m de espessura, é constituída por calcários finos betuminosos, folhelhos betuminosos, pelitos vermelhos e cementstones com leques de cristais de calcita (pseudomorfos de aragonita) e laminação plana, interrompida localmente por brechas e estruturas de deformação. A base da Formação Guia é considerada como a porção calcária da capa carbonática Puga (Nogueira et al. 2007). A Formação Serra do Quilombo, com 100m de espessura, é composta predominantemente por brechas com cimento dolomíticos e/ou com matriz intercaladas com dolomitos finos e dolomitos arenosos com estratificação cruzada hummocky, interpretada como depósitos de plataforma moderadamente rasa a profunda afetada por sismos e tempestades. A Formação Nobres consiste em dolomitos finos, dolomitos oolíticos subordinados e estromatólitos, além de dolomitos arenosos, brechas, ritmitos arenito/pelito e arenitos que são interpretados como depósitos de planície de maré/sabkha. Os carbonatos são sobrepostos discordantemente pelas rochas siliciclásticas do Grupo Alto Paraguai (Fig. 1).

$\mathrm{Na}$ região sul do Cráton Amazônico afloram apenas as formações Mirassol d'Oeste e Guia encontradas na mina Terconi, na região de Mirassol d'Oeste, e na mina Calcário Tangará, na região de Tangará da Serra (Nogueira \& Riccomini 2006). Dados isotópicos $\left(\delta^{13} \mathrm{C}\right.$ e $\left.{ }^{87} \mathrm{Sr} /{ }^{86} \mathrm{Sr}\right)$ foram apresentados por Alvarenga et al. (2008) para a Mina Calcário Tangará.

A idade mínima para a deposição das rochas sedimentares neoproterozóicas que afloram no sudoeste do Cráton Amazônico e Faixa Paraguai é de $483 \pm 8 \mathrm{Ma}$ (método Rb/Sr; Almeida \& Mantovani 1975) e de $504 \pm$ 12 Ma (método K/Ar; Amaral 1966) obtida para o Granito São Vicente, que corta as rochas metassedimentares do Grupo Cuiabá, que servem de embasamento para o diamictito Puga, aflorante na Faixa Paraguai (Fig. 1). A assembléia de microfósseis encontrados na Formação Mirassol d'Oeste é caracterizada por Siphonophycus capitaneum, S. robustum filamentos de cianobactérias 


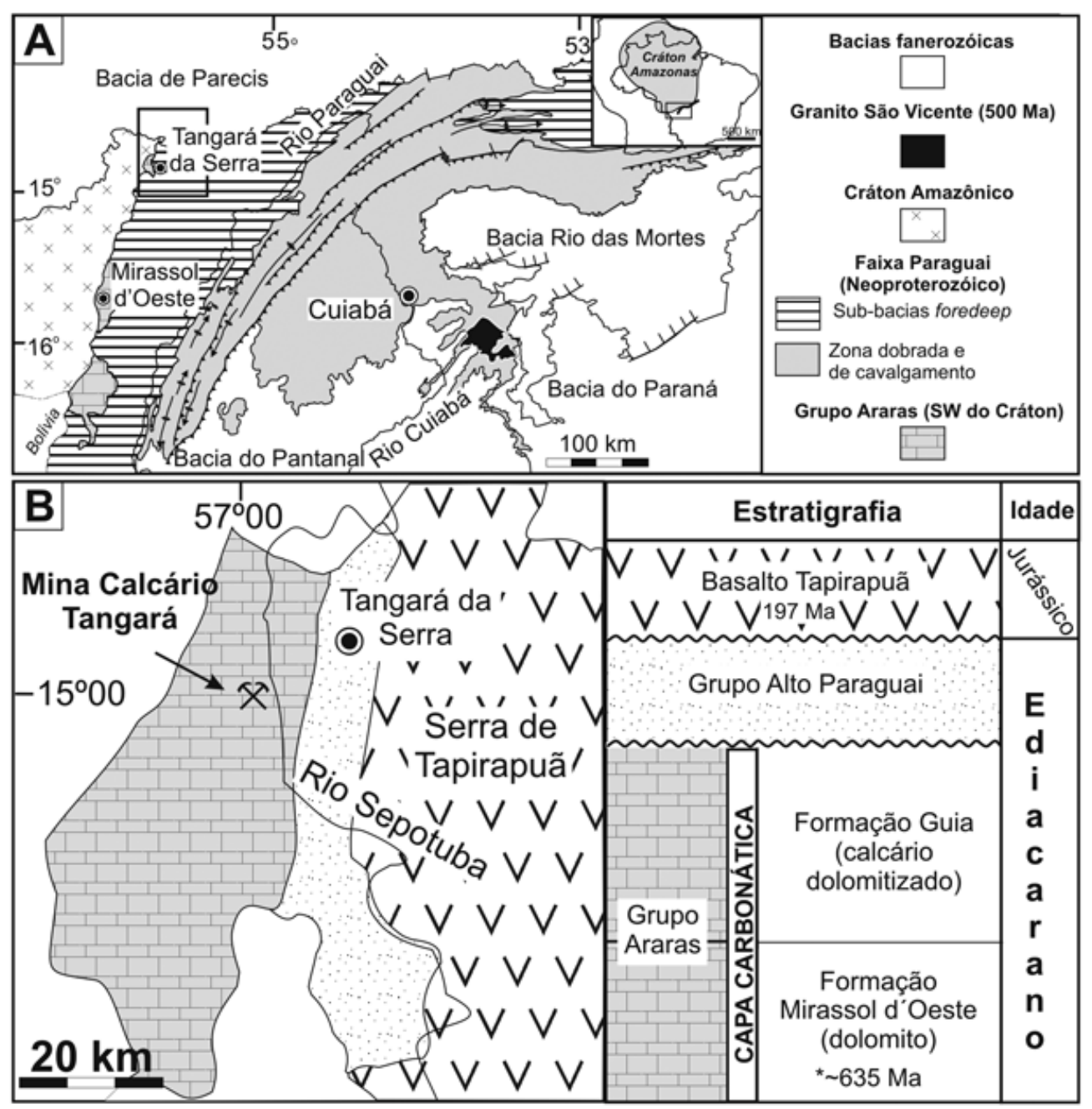

Figura 1 - O sul do Cráton Amazônico e norte da Faixa Paraguai. A) Contexto geotectônico. B) Mapa geológico simplificado da região de Tangará da Serra e da mina Calcário Tangará. Os diamictitos da Formação Puga ocorrem somente na região de Mirassol d'Oeste. Modificado de Valente et al. (2004) e Nogueira \& Riccomini (2006).

e Dictyotidium minor. Na Formação Guia predominam Leiosphaeridia minutissima e L. crassa. E fragmentos de acritarcos ediacaranos como Appendisphaera sp, $\mathrm{Ca}$ vaspina sp e Cavaspina acuminate, e o acantomorfo do gênero Tanarium registrado na Formação Nobres (Hidalgo et al. 2008). Estas assembléias indicam duas palinofloras de acritarcos ediacaranos - Ediacaran Leiosphere Palynoflora - ELP, e Ediacaran Complex Acanthomorph Palynoflora - ECAP de Grey (2005).

MÉTODOS A descrição de fácies seguiu a proposição de Walker (1992) e Kerans \& Tinker (1997). Análises petrográficas e mineralógicas foram utilizadas como informações complementares para a interpretação ambiental da sucessão estudada. As lâminas foram tingidas com Alizarina Vermelha-S a uma concentração de $0,2 \mathrm{~g} / 100 \mathrm{ml}$ de 1,5\% de ácido hidroclorídrico para a determinação da presença de calcita e dolomita (Adams et al. 1984), auxiliada pela difratometria de raios-X para a identificação de outras composições mineralógicas. A porcentagem do material insolúvel foi obtida pela dissolução dos carbonatos em ácido hidroclorídrico a $10 \%$.

FÁCIES DEPOSICIONAIS A sucessão estudada possui aproximadamente $20 \mathrm{~m}$ de espessura e inclui o topo da Formação Mirassol d'Oeste e base da Formação Guia. Foram descritas 9 fácies que correspondem dolograinstones peloidais, calcários terrígenos e com leques de cristais, folhelhos betuminosos, siltitos e brechas intraformacionais (Tab. 1). Processos de dissolução por pressão são indicados por estilólitos e o neomorfismo e a dolomitização (esta nos calcários da Formação Guia) têm modificado a textura micrítica e espática original de algumas fácies. Embora a mina estudada diste $100 \mathrm{~km}$ da mina Terconi, seção tipo da base do Grupo Araras, é similar no que se refere a fácies, arquitetura de fácies, e nos valores negativos de ${ }^{13} \mathrm{C}$ (-4\%o a -7\%o; Soares 2008) e sobretudo por depósitos transgressivos de platafor- 
Tabela 1 - Resumo das características das associações de fácies com destaque para fácies componentes, estruturas, processos e interpretação.

\begin{tabular}{|c|c|c|c|c|c|}
\hline $\mathrm{N}^{\mathrm{o}}$ & Associação de Fácies & Fácies & Estruturas & Processo & Interpretação \\
\hline \multirow[b]{2}{*}{1} & \multirow{2}{*}{$\begin{array}{l}\text { Plataforma rasa a } \\
\text { moderadamente } \\
\text { profunda } \\
\text { influenciada por } \\
\text { onda }\end{array}$} & $\begin{array}{l}\text { Dpp - } \\
\text { Dolograinstone } \\
\text { peloidal com } \\
\text { laminação plana } \\
\text { paralela }\end{array}$ & $\begin{array}{l}\text { Laminação plano } \\
\text { paralela, laminação } \\
\text { de baixo ângulo, } \\
\text { estilólitos, micro e } \\
\text { macropelóides. }\end{array}$ & $\begin{array}{l}\text { Predomínio de suspensão com } \\
\text { esporádicos fluxos oscilatórios. } \\
\text { Nucleação do carbonato seguido } \\
\text { de rápida cimentação }\end{array}$ & \multirow{2}{*}{$\begin{array}{l}\text { Alternância de precipitação } \\
\text { química, suspensão e fluxos } \\
\text { oscilatórios. Intensa atividade } \\
\text { biológica é indicada pela } \\
\text { abundância de pelóides. } \\
\text { Estruturas produzidas por onda } \\
\text { podem representar uma maior } \\
\text { proximidade da base da onda. }\end{array}$} \\
\hline & & $\begin{array}{l}\text { Dto - } \\
\text { Dolograinstone } \\
\text { peloidal com } \\
\text { laminação quase } \\
\text { planar com } \\
\text { truncamentos de } \\
\text { baixo ângulo }\end{array}$ & $\begin{array}{l}\text { Laminação quase } \\
\text { planar com } \\
\text { truncamento de } \\
\text { baixo ângulo, micro } \\
\text { e macropelóides. }\end{array}$ & $\begin{array}{l}\text { Fluxos oscilatórios de alta } \\
\text { velocidade. Nucleação de } \\
\text { carbonato e rápida cimentação. }\end{array}$ & \\
\hline \multirow{2}{*}{2} & \multirow{2}{*}{$\begin{array}{l}\text { Plataforma mista } \\
\text { moderadamente } \\
\text { profunda dominada } \\
\text { por corrente e onda }\end{array}$} & $\begin{array}{l}\text { Ctm - Calcário fino } \\
\text { com grãos terrígenos } \\
\text { e acamamento de } \\
\text { megamarca ondulada }\end{array}$ & $\begin{array}{l}\text { Megamarcas } \\
\text { onduladas, } \\
\text { marcas onduladas, } \\
\text { laminação convoluta } \\
\text { e mud drapes. }\end{array}$ & $\begin{array}{l}\text { Migração de formas de leito } \\
\text { geradas por correntes e ondas. } \\
\text { Periódico influxo continental de } \\
\text { grãos terrígenos. }\end{array}$ & \multirow{2}{*}{$\begin{array}{l}\text { Migração de formas de leito } \\
\text { geradas por corrente seguido } \\
\text { de retrabalhamento por fluxos } \\
\text { oscilatórios. Rápida mudança } \\
\text { na energia de fluxo é indicada } \\
\text { por intercalações de siltitos } \\
\text { e calcários. A presença de } \\
\text { megamarcas onduladas e } \\
\text { a abundância de terrígenos } \\
\text { sugerem deposição influenciada } \\
\text { por ondas e com influxo de } \\
\text { terrígenos }\end{array}$} \\
\hline & & $\begin{array}{l}\text { Sml - Siltito maciço } \\
\text { e laminado }\end{array}$ & Laminação plana & Deposição por suspensão & \\
\hline \multirow{3}{*}{3} & \multirow{3}{*}{$\begin{array}{l}\text { Plataforma profunda } \\
\text { supersaturada } \\
\text { em } \mathrm{CaCO}_{3} \text { com } \\
\text { fornecimento } \\
\text { esporádico de } \\
\text { material terrígeno }\end{array}$} & $\begin{array}{l}\mathrm{Cl} \text { - Calcário fino } \\
\text { com grãos marcas } \\
\text { onduladas e leques } \\
\text { de cristais }\end{array}$ & $\begin{array}{l}\text { Leques de cristais, } \\
\text { marcas onduladas, } \\
\text { laminações } \\
\text { convolutas e } \\
\text { camadas deformadas. }\end{array}$ & $\begin{array}{l}\text { Crescimento de cristais em } \\
\text { águas supersaturadas em } \mathrm{CaCO}_{3} \text {, } \\
\text { esporadicamente influenciadas } \\
\text { por correntes. }\end{array}$ & \multirow{3}{*}{$\begin{array}{l}\text { Supersaturação de } \mathrm{CaCO}_{3} \mathrm{em} \\
\text { águas profundas relacionada } \\
\text { ao aumento da alcalinidade, } \\
\text { mudanças na circulação e } \\
\text { temperatura oceânica e } \mathrm{CO}_{2} \\
\text { atmosférico, além de uma baixa } \\
\text { taxa de sedimentação. Marcas } \\
\text { onduladas e folhelhos sugerem } \\
\text { ação de ondas e intervalos } \\
\text { de sedimentação pelítica. } \\
\text { Diques neptunianos e camadas } \\
\text { deformadas isoladas sugerem } \\
\text { atividade sísmica durante a } \\
\text { deposição. }\end{array}$} \\
\hline & & $\begin{array}{l}\mathrm{Fb}-\text { Folhelho } \\
\text { betuminoso }\end{array}$ & $\begin{array}{l}\text { Laminação plano } \\
\text { paralela }\end{array}$ & Deposição a partir de suspensão & \\
\hline & & $\begin{array}{l}\text { Bd - Brecha calcária } \\
\text { preenchendo dique } \\
\text { neptuniano }\end{array}$ & $\begin{array}{l}\text { Diques neptunianos, } \\
\text { clastos angulosos } \\
\text { dispostos de forma } \\
\text { caótica ou orientados }\end{array}$ & $\begin{array}{l}\text { Fragmentação dos calcários } \\
\text { da Formação Guia seguida de } \\
\text { deposição pelítica. Associada } \\
\text { com fraturamento e dilatação } \\
\text { causada por abalos sísmicos. }\end{array}$ & \\
\hline \multirow[b]{2}{*}{4} & \multirow[b]{2}{*}{ Talude } & $\begin{array}{l}\text { Bc - Brecha calcária } \\
\text { intraformacional }\end{array}$ & $\begin{array}{l}\text { Clastos angulosos } \\
\text { dispostos } \\
\text { caoticamente }\end{array}$ & $\begin{array}{l}\text { Fraturamento e fragmentação } \\
\text { dos dolomitos e calcários das } \\
\text { formações Mirassol d'Oeste e } \\
\text { Guia durante movimentação de } \\
\text { massas parcialmente litificadas. }\end{array}$ & \multirow{2}{*}{$\begin{array}{l}\text { Movimentos verticais associado } \\
\text { à instabilidade gravitacional em } \\
\text { uma rampa submarina profunda, } \\
\text { gerada pelo acúmulo em excesso } \\
\text { de carbonato. }\end{array}$} \\
\hline & & $\begin{array}{l}\text { Ce - Calcário } \\
\text { com estruturas de } \\
\text { escorregamento }\end{array}$ & $\begin{array}{l}\text { Estruturas de } \\
\text { escorregamento, } \\
\text { fraturas, camadas } \\
\text { deformadas } \\
\text { e laminações } \\
\text { convolutas }\end{array}$ & $\begin{array}{l}\text { Movimento gravitacional de } \\
\text { massas }\end{array}$ & \\
\hline
\end{tabular}

ma carbonática. Três superfícies estratigráficas foram identificadas na sucessão estudada (Fig. 2): o contato entre as unidades Mirassol d'Oeste e Guia (S1) interpretada como uma superfície transgressiva indicada por recobrimento em onlap de pelitos da base da Formação Guia (Fig. 2, Perfil II); e dois limites de fácies (S2 e S3) dentro da Formação Guia. Intervalos com deformação sinsedimentar (A, B e C) são indicados na sucessão por falhas sin-sedimentares, brechas, diques neptunianos, camadas deformadas e laminações convolutas (Fig. 2).
Dolograinstone peloidal com laminação plano paralela - Dpp Esta fácies forma camadas lateralmente contínuas por algumas dezenas de metros, é composta por dolograinstones peloidais de cor rosada e granulação fina a média. Apresentam laminação plano paralela, que localmente passa para laminação de baixo ângulo e, algumas vezes, é marcada por planos de estilólitos (Fig. 3A e B). Variações de espessura da laminação nos dolomitos refletem os diferentes tamanhos dos pelóides de dolomita microcristalina e a presença de cimento dolomítico. As laminações mais delgadas com espessuras 


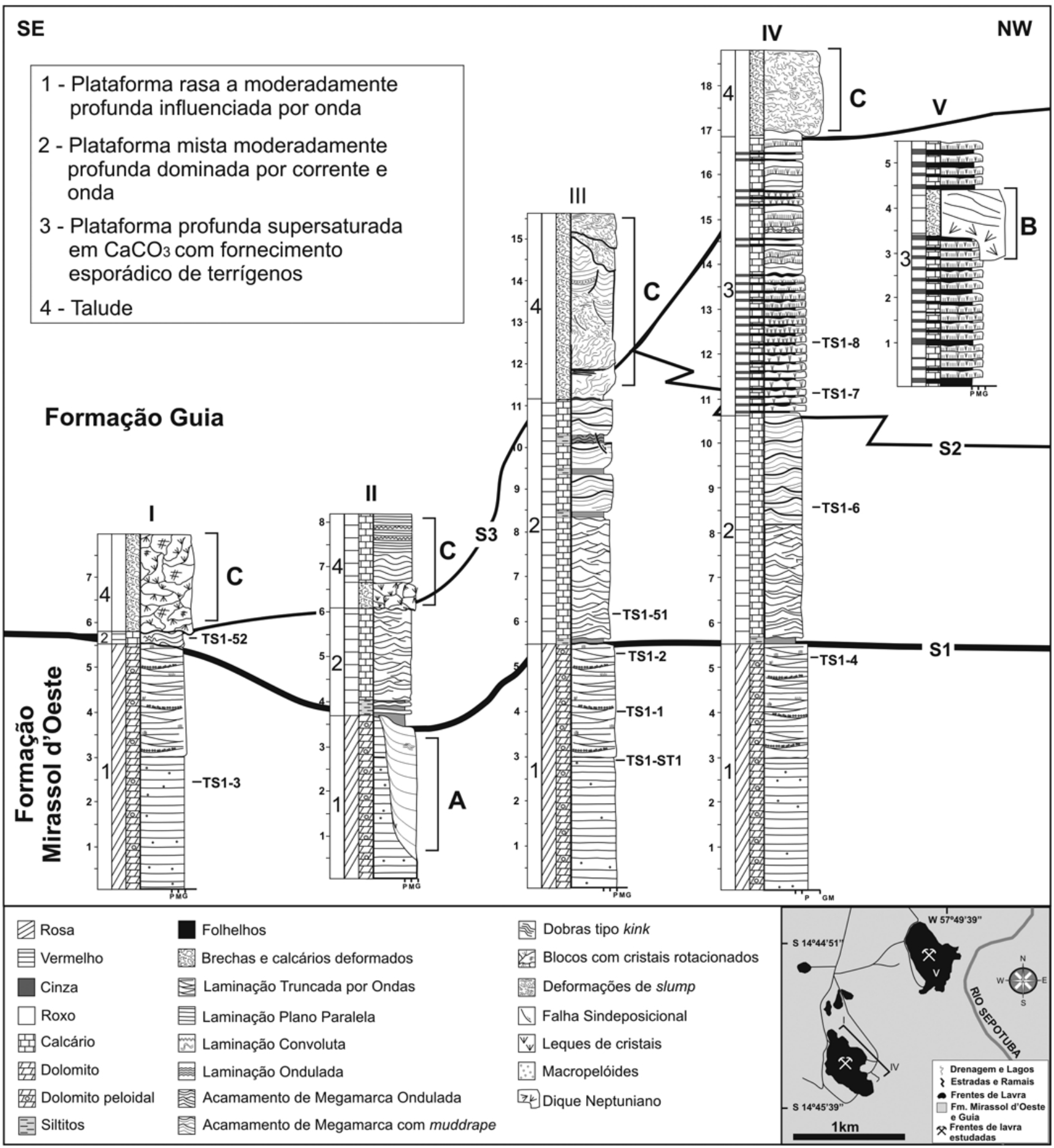

Figura 2 - Perfis Estratigráficos da capa carbonática da mina Calcário Tangará. A sucessão dolomítica da Formação Mirassol d'Oeste é separada pela superfície S1 e as superfícies S2 e S3 são limites entre associações de fácies. Zonas de deformação são indicadas pelas letras A, B e C. Siglas TS-1 posicionam as amostras coletadas. Quadro abaixo a direita com o posicionamento dos perfis na área da Mina Calcário Tangará.

de $\sim 1,5 \mathrm{~mm}$ apresentam um arcabouço formado de micropelóides $(<1 \mathrm{~mm})$ com reduzido espaço intergranular com pouco ou nenhum cimento. Laminações mais espessas com até $5 \mathrm{~mm}$ apresentam micropelóides e raros macropelóides (2-3 $\mathrm{mm}$ ) compondo um arcabouço mais poroso. O cimento de dolomita unimodal com textura xenotópica ocorre preenchendo porosidade interpeloi- dal que consiste de $10 \%$ a $30 \%$ de poros da rocha (Fig. 3D). Estruturas deformacionais sin-sedimentares como falhas e dobras kink ocorrem localmente.

A laminação plano paralela é produto de deposição onde havia o predomínio de suspensão e que era esporadicamente influenciada localmente por movimentos oscilatórios que também geraram laminações 

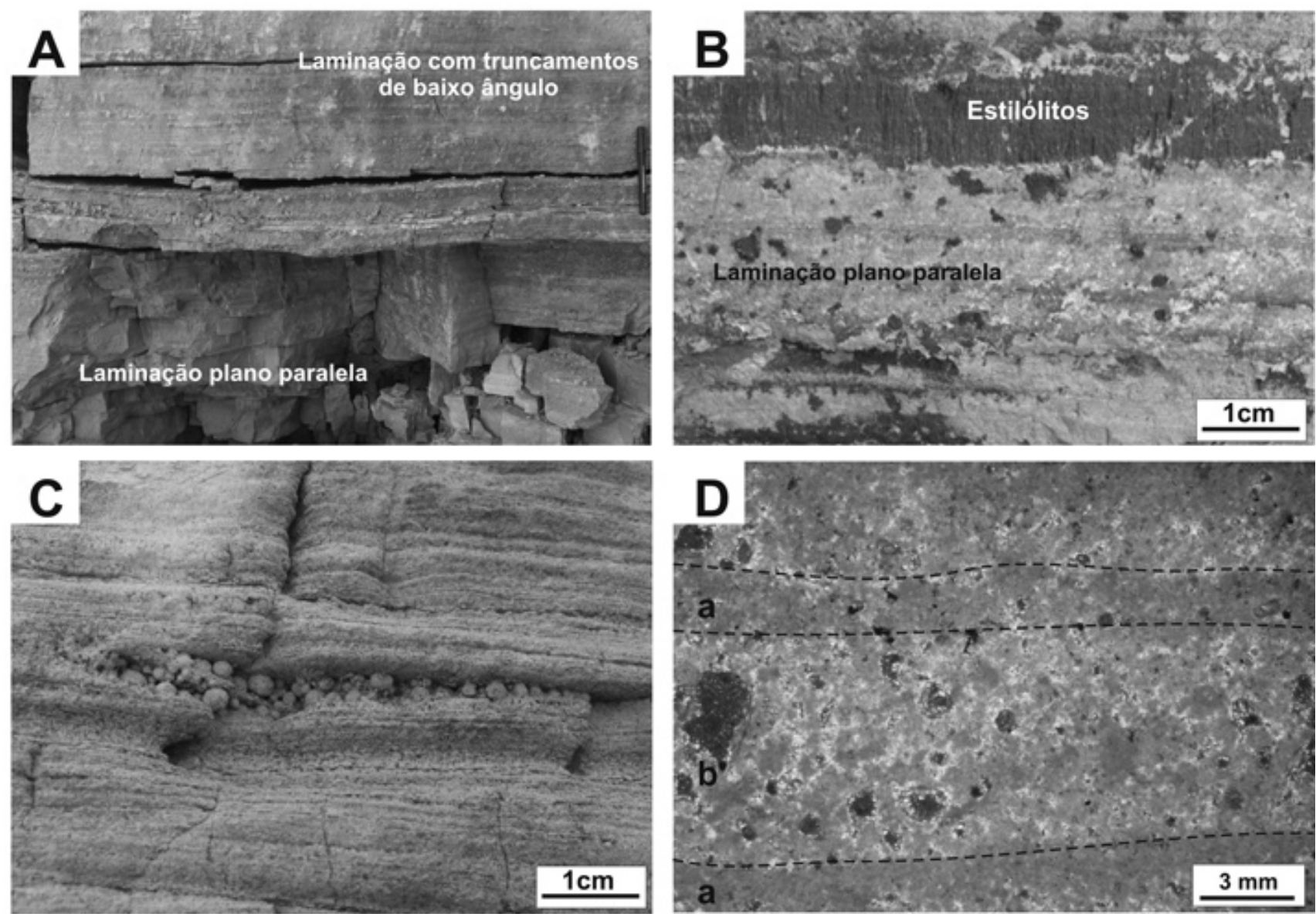

Figura 3 - Aspecto faciológico da Formação Mirassol d'Oeste. A) Limite entre as fácies Dpp e Dto; B) Detalhe dos dolomitos com laminação plano paralela e estilólitos; C) Macropelóides entre as laminações com truncamentos por onda; D) Lâminas de dolograinstone formadas por micropelóides sem cimento (a) e com cimento dolomítico (b).

de baixo ângulo (De Raaf et al. 1977). Nesta fase de deposição por suspensão a lama microcristalina foi inibida permitindo a cimentação espática. A presença de pelóides é quase sempre interpretada como produto de atividade biológica que induz a nucleação do carbonato, porém pelóides são comuns em quase todos os ambientes carbonáticos recentes e antigos, e sua origem pode estar relacionado a outros fatores como crescimento a partir de núcleos de grãos detriticos e precipitação inorgânica (Tucker 1992), em rochas carbonáticas neoproterozóicas estes componentes são interpretados como de origem biológica (James et al. 2001). A ocorrência de macropelóides é produto da agregação de micropelóides pela movimentação em fundo oceânico e implicam em reduzida abrasão durante sua formação, já que estas partículas são facilmente desagregadas. A preservação deste componente indica que houve pouco ou nenhum transporte o que sugere que a deposição foi in situ e/ou que está relacionada a uma rápida cimentação (James et al. 2001, Halverson et al. 2004).

Dolograinstone peloidal com laminação quase planar e truncamentos por onda - Dto Esta fácies é composta por dolograinstone peloidal rosa esbran- quiçados de granulação média a grossa, caracterizados pela presença de laminação quase planar com truncamentos de baixo ângulo por ondas. Micropelóides consistem o componente principal da fácies com até $1 \mathrm{~mm}$ de diâmetro e geralmente exibem um aspecto grumoso (Fig. 3D). Macropelóides constituem aglomerado de micropelóides, são esféricos e subesféricos e variam de 5 a $2 \mathrm{~mm}$ de diâmetro, formando lentes entre as laminações truncadas (Fig. 3C). Os espaços interpeloidais ( $20 \%$ a $30 \%$ da rocha) são ocupados predominantemente por dolomita equidimensional com textura xenotópica e raros cristais de dolomita romboédrica. A textura da rocha é definida por alternância de lâminas com micropelóides (base) e macropelóides (topo) (Fig. 3C e D). Deformações sin-sedimentares como falhas normais e dobras kink são comuns nesta fácies (Zona A; Fig. 2).

As laminações quase planar a ondulada com truncamentos de baixo ângulo indicam fluxos oscilatórios de alta velocidade que induziram eventos erosivos sobre os depósitos peloidais (De Raaf et al. 1977 e Arnott et al. 1995). A preservação de macropelóides é interpretada da mesma forma que a fácies Dto. O deslocamento subvertical das falhas sin-sedimentares gerou 
um encurtamento horizontal que lateralmente deformou os dolomitos peloidais formando as dobras tipo-kink.

Calcário cristalino com terrígenos e acamamento de megamarca ondulada - Ctm A fácies Ctm é caracterizada por calcários finos dolomitizados com até 30\% de terrígenos (quartzo tamanho areia fina e silte) de cor vermelha com acamamento de megamarcas onduladas assimétricas que apresentam localmente muddrapes preservando a morfologia (Fig. 4A). A rocha é composta por $80 \%$ de calcita microespática e localmente dolomita fina. Grãos terrígenos tamanho areia fina (quartzo arredondado e mica) são disseminados e perfazem cerca de $2 \%$ e $5 \%$ do arcabouço enquanto que o de tamanho silte compõem cerca de $25 \%$. Cavidades e vugs são preenchidos por cristais romboédricos de dolomita e calcita espática, geralmente disposta na borda desta porosidade, ambas são algumas vezes, associada com betume degradado (Fig. 5A). As megamarcas de maior amplitude têm $35 \mathrm{~cm}$ e um comprimento de onda de 1,3 $\mathrm{m}$, enquanto as de amplitudes de $11 \mathrm{~cm}$ e comprimento de no máximo $1,10 \mathrm{~m}$ são as mais comuns. Marcas onduladas assimétricas $(\mathrm{h}=1 \mathrm{~cm} \mathrm{e}=5 \mathrm{~cm})$ ocorrem de forma mais isolada aparentemente associada aos topos do acamamento de megamarcas. Lateralmente está fácies apresenta uma disposição cíclica das camadas, geralmente associada a camadas de siltitos de até $10 \mathrm{~cm}$ que recobrem as megamarcas onduladas. Laminações convolutas ocorrem localmente.

$\mathrm{O}$ acamamento de megamarcas onduladas foi gerado pela migração de formas de leito formada por correntes e induzida por ondas (De Raaf et al. 1977). A presença de grãos terrígenos finos e subarredondados sugere influxo continental. O acamamento de megamarcas onduladas é geralmente individualizado por pelito o que sugere deposição em uma zona de baixa energia relacionada a transição ou offshore proximal (Aigner 1985, Faulkner 1988).

\section{Calcário cristalino com marcas onduladas e leques} de cristais - Cl Esta fácies forma um conjunto de camadas tabulares com o topo ondulado constituídos por calcários finos cristalinos rosados com leques de cristais de calcita (pseudomórficos de aragonita) geralmente intercaladas com os folhelhos da fácies $\mathrm{Fb}$ (Fig. 4B). Diques neptunianos ocorrem cortando as camadas
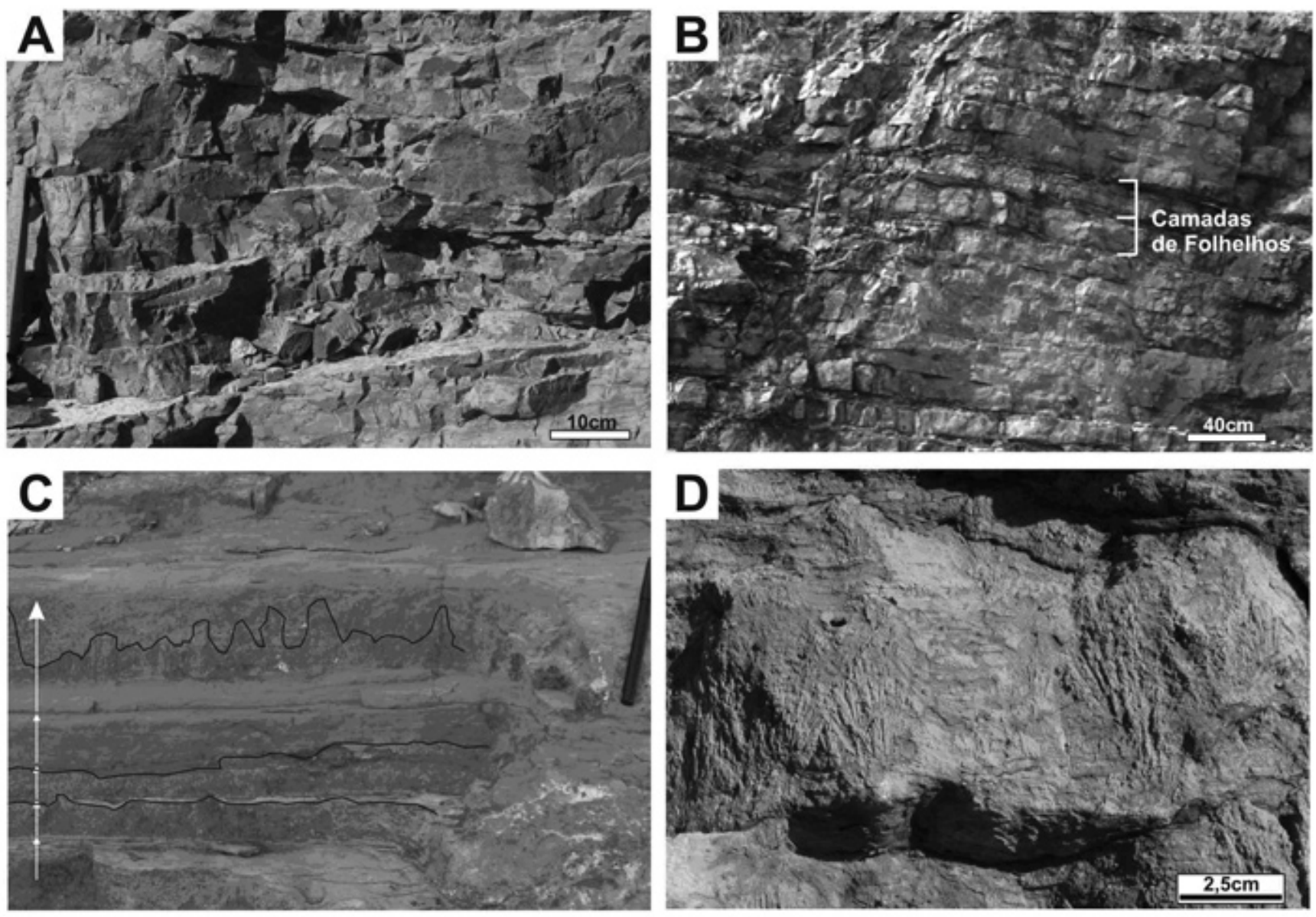

Figura 4 - Aspecto faciológico da Formação Guia. A) Calcários finos dolomitizados com acamamento de megamarcas onduladas; B) Camadas tabulares com topo ondulado de calcários finos com leques de cristais intercalados com camadas de folhelhos; C) Ciclos (setas) formados por cristais e calcários cristalinos com laminações onduladas; D) Leques de cristais de calcita (pseudomorfos de aragonita). 
desta fácies (ver fácies Bd). Camadas deformadas (acamamento convoluto) entre camadas sem deformação ocorrem lateralmente aos diques neptunianos. O calcário cristalino está parcialmente dolomitizado o que dificulta a determinação da fábrica original, porém a forma dos leques de cristais e laminações internas não foram obliteradas (Fig. 4D). Os leques de cristais desta fácies são muito semelhantes aos que são encontrados nas capas carbonáticas neoproterozóicas de outras partes do mundo (Clough \& Goldhammer 2000, James et al. 2001, Hoffmann \& Schrag 2002, Corsetti et al. 2004, Lorentz et al. 2004). São rosados, constituídos de calcita espática neomórfica, aciculares radiais em forma de leque (Figs. 4C-D e 5B).

Os cristais podem ser também colunares isolados ou lateralmente conectados por delgados arranjos de cristais fibrosos (Fig. 4C-D). Os leques de cristais fibrosos colunares nos primeiros níveis de ocorrência apresentam comprimentos de até $5 \mathrm{~cm}$, são muito abundantes e comumente ocorrem isolados (Fig. 4D). Em direção ao topo da sucessão os cristais desconectados ficam mais abundantes e são cobertos por calcários com laminações onduladas e quase planar (Fig. 4C). Entre leques de cristais colunares conectados ocorrem laminações convexas que consistem de delgadas intercalações de siltito e carbonato em camadas com topo ondulado (Fig. 4D). As marcas onduladas apresentam padrão de interferência e comprimentos de onda de até $4 \mathrm{~cm}$ com amplitudes de $3 \mathrm{~mm}$.

A forma convexa das laminações indica que a deposição destes sedimentos ocorreu provavelmente de forma simultânea, ou antes, da formação dos cristais, e a convexidade seria formada através do rompimento das laminações durante o crescimento dos cristais. A base dos cristais é comumente plana e concordante com a laminação planar, porém onde a superfície é ondulada a base dos cristais é irregular. Pequenos ciclos de leques de cristais com muddrapes e laminações onduladas são comuns e representam sucessivos estágios de precipitação aragonítica e sedimentação (Fig. 4C).

A abundância de cristais sugere que esta fácies foi formada em um ambiente supersaturado em $\mathrm{CaCO}_{3}$, com alta alcalinidade e provavelmente de águas calmas e profundas logo abaixo da interface água-sedimento (Corsetti et al. 2004, Lorentz et al. 2004). As principais causas para a precipitação de aragonita seriam mudanças na circulação e temperatura oceânica e na $\mathrm{CO}_{2}$ atmosférico, que juntos produziriam um rápido aumento na saturação de aragonita (Sumner 2002). A taxa de sedimentação também seria outro fator importante já que os pseudomorfos de aragonita são encontrados em ambientes deposicionais com baixa taxa de sedimentação. A forma de crescimento dos cristais ocorreu provavelmente de duas formas distintas: 1) os cristais, geralmente isolados, cresceram no fundo aquosos e posteriormente foram soterrados por material carbonático e seu topo fragmentado pela ação de correntes, estes cristais estariam associados à rápida precipitação $\mathrm{e}$ pouca ou nenhuma sedimentação que favoreceria o seu crescimento até atingir tamanhos centimétricos; 2) os
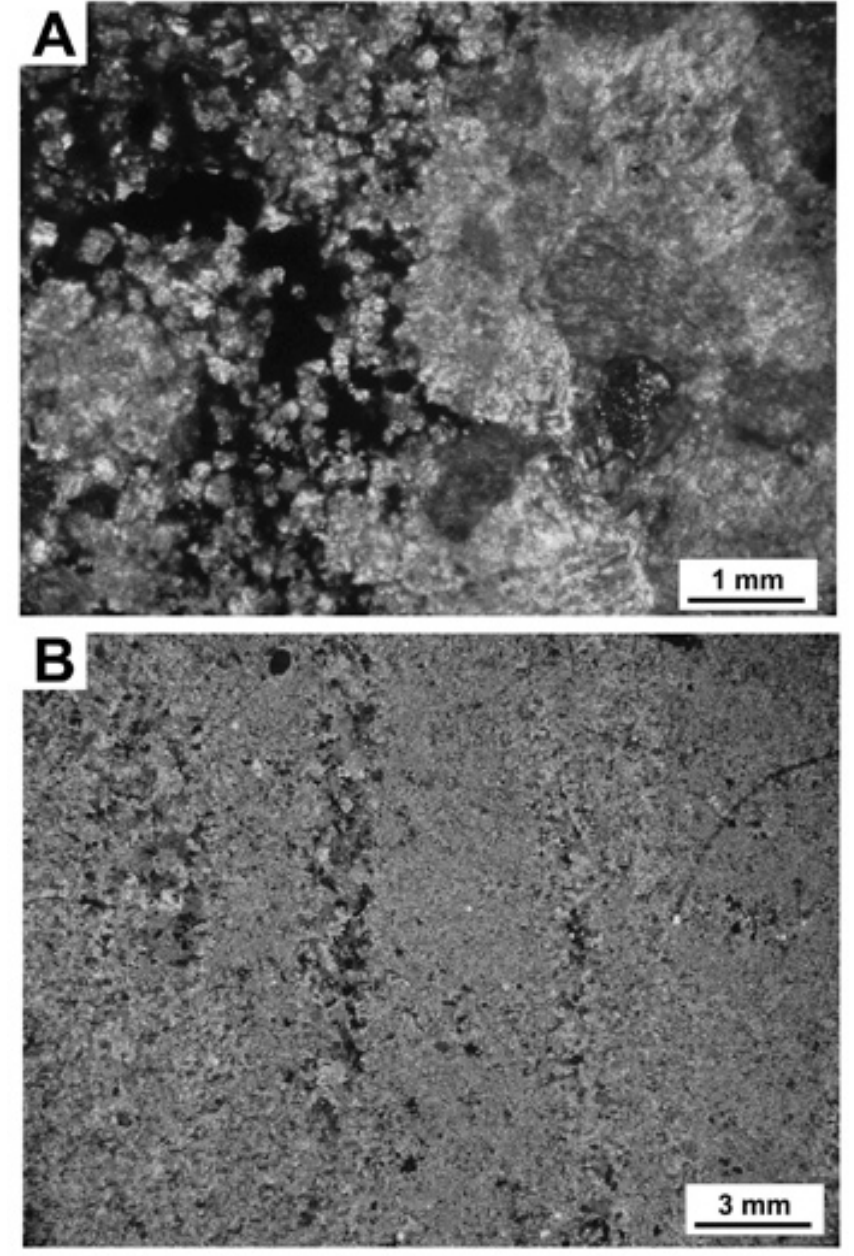

Figura 5 - Aspectos petrográficos da capa calcária de Tangará da Serra. A) Calcita espática na borda de cavidade preenchida por dolomita romboédrica e betume; B) Cristais de calcita interpretados como aragonita em matriz microcristalina parcialmente dolomitizado.

cristais, principalmente os conectados, cresceram após ou durante a deposição e romperam as laminações préexistentes, estariam relacionados aos ambientes com aumento da taxa de sedimentação e a entrada de terrígenos (onde ocorrem estes cristais as camadas mais espessas dos folhelhos da fácies $\mathrm{Fb}$ estão presentes). Estas duas formas de crescimento podem ser associadas a diferentes taxas de sedimentação.

A presença de pequenas marcas onduladas no topo das camadas com cristais indica correntes fracas em um ambiente de águas tranqüilas com certa profundidade. Processos diagenéticos como neomorfismo e dolomitização são comuns nesta fácies. O neomorfismo ocorreu primeiro alterando os cristais de aragonita para calcita espática (Fig. 5B). A dolomitização é um processo bem posterior a deposição onde somente o micrito foi dolomitizado enquanto os cristais neomórficos se preservaram (Fig. 5B). A geração desta fácies está relacionada a mudanças cíclicas, que iniciam com a sedimentação pelitíca e carbonática, seguida do crescimento 
dos cristais de aragonita cujas porções mais superiores foram parcialmente destruídas pela ação de correntes. A presença de diques neptunianos e camadas deformadas isoladas sugerem a influencia de eventos de sismicidade comumente encontrados em ambientes de plataforma marinha (Obermeier 1996) (Zona B; Fig. 2).

Folhelho betuminoso - Fb Folhelhos betuminosos apresentam coloração que varia do preto ao cinza e se encontram impregnadas de betume. As camadas variam de espessura, as mais delgadas apresentam $0,5 \mathrm{~cm}$ de espessura, enquanto as mais espessas podem alcançar até $10 \mathrm{~cm}$. Estas camadas apresentam fissilidade e laminação bem desenvolvida e são geralmente muito contínuas e tabulares, intercalando-se, de forma cíclica, com camadas de calcários finos da fácies $\mathrm{Cl}$ (Fig. 4B). A formação desta fácies esta relacionada a interrupções cíclicas na sedimentação carbonática seguido de acúmulo de material pelitíco em águas parcialmente estagnadas e profundas com preservação expressiva de matéria orgânica posteriormente maturada na forma de betume.

Siltito maciço e laminado - Sml Esta fácies é constituída por siltitos vermelhos maciços que localmente apresentam laminação planar e fissilidade pouco desenvolvida que acompanha o acamamento. O corpo é lateralmente descontínuo com espessuras entre $20 \mathrm{~cm}$ e $1.60 \mathrm{~m}$ e se intercala com calcários finos com megamarcas onduladas (fácies $\mathrm{Ctm}$ ). A cor vermelha denuncia óxidos/hidróxidos de ferro. A disposição em onlap destes depósitos com os dolograinstones peloidais indica preenchimento de depressões de um paleorelevo (Fig. 2). Intercalações com os calcários sugerem alternâncias na energia do fluxo em um ambiente de águas profundas.

Brecha calcária - Bc Brechas calcárias de arcabouço aberto ocorrem formando camadas descontínuas de até $2 \mathrm{~m}$ de espessura em calcários deformados. Exibem clastos retangulares dispostos caoticamente e que ocorrem como fragmentos angulosos mal selecionados, de formas alongadas com tamanhos centimétricos. A brecha é composta predominantemente de fragmentos de dolomitos de cor rosada da Formação Mirassol d'Oeste e calcários de cor cinza a vermelha da Formação Guia. A matriz intersticial é de natureza carbonática, maciça e de cor rosa avermelhado. Os clastos das duas unidades ocorrem comumente próximos ao contato com a Formação Mirassol d'Oeste, base da sucessão carbonática em Tangará da Serra.

A brecha foi formada a partir do fraturamento e fragmentação dos dolomitos e calcários das formações Mirassol d'Oeste e Guia durante movimentação de massas parcialmente litificadas. A proximidade com o topo da Formação Mirassol d'Oeste sugere um curto deslocamento dos clastos de dolomito. A matriz carbonática foi depositada de forma contemporânea ao deslocamento dos clastos.

Brecha calcária em dique neptuniano-Bd Brechas calcárias de arcabouço aberto e fechado que preenchem diques neptunianos cuja origem relaciona-se a falhas normais (Fig. 6A). Os clastos são predominantemente retangulares e ocorrem como fragmentos angulosos mal selecionados, de formas alongadas e achatadas com tamanhos centimétricos (Fig. 6B). A composição dos clastos é predominantemente de fragmentos de argilitos de cores esbranquiçadas e calcários cinza da Formação Guia. A matriz intersticial é de natureza pelítica, maciça e de cor vermelha. Os clastos apresentam comumente disposição caótica, porém quando próximos a encaixante (Formação Guia) apresentam uma disposição paralela ao contato.

Está fácies foi gerada a partir do fraturamento e fragmentação dos calcários da Formação Guia seguida de deposição pelítica. Devido à ausência de feições que indiquem exposição subaérea na área de estudo, relaciona-se a origem das brechas que preenchem os diques neptunianos ao fraturamento e dilatação causada por abalos sísmicos em águas profundas (Zona B; Fig. 2).

Calcários com estruturas de escorregamento Ce Está fácies é composta por calcários finos de cor rosa esbranquiçado com laminações convolutas, fraturas e estruturas de escorregamento (slump), estas últimas constituem as feições de deformação predominantes na fácies. Os depósitos apresentam geralmente espessuras de $1 \mathrm{~m}$, mas localmente podem alcançar até $4 \mathrm{~m}$, são lateralmente descontínuos e ocorrem sempre sobre camadas sem deformações (Zona C; Fig. 2). O contato entre as camadas deformadas e sem deformação são comumente irregulares e com planos de falha. Camadas tabulares suavemente deformadas podem ser observadas nestes depósitos, assim como camadas interrompidas formando blocos métricos. Acamamentos convolutos se desenvolvem em camadas pelíticas intercaladas com calcários laminados que ocorrem de forma mais restrita (Fig. 6C). A base destas camadas convolutas são comumente planas, sem ou com pouca deformação. Falhas sin-sedimentares de até $1 \mathrm{~m}$ ocorrem ao longo de toda a fácies e formam lateralmente pequenas corrugações.

Dobras convolutas são estruturas de deformação muito complexas que podem ser geradas principalmente por processos de sobrecarga ou deslizamento (slumping) (Lowe 1975). Na Formação Guia, em Tangará da Serra, o fato de as camadas convolutas ocorrerem entre camadas sem deformação sugere que a deformação foi contemporânea à deposição, ocasionada pela liquefação e/ou sobrecarga de camadas com maior densidade (calcarenitos) sobre camadas plásticas e de menor densidade (pelito carbonático) (Visher \& Cunningham 1981, Mills 1983). Estruturas de escorregamento são geradas por movimentos gravitacionais de massas sedimentares sobre discretos planos basais inclinados (Coleman \& Prior 1988, Mulder \& Cochonat 1996). Camadas deformadas de calcário fino, falhas sin-sedimentares, blocos e camadas interrompidas (associada às estruturas de escorregamento), são produtos de fraturamento e escorregamentos de massas parcialmente litificadas. Esta instabilidade gravitacional foi gerada em declives de 

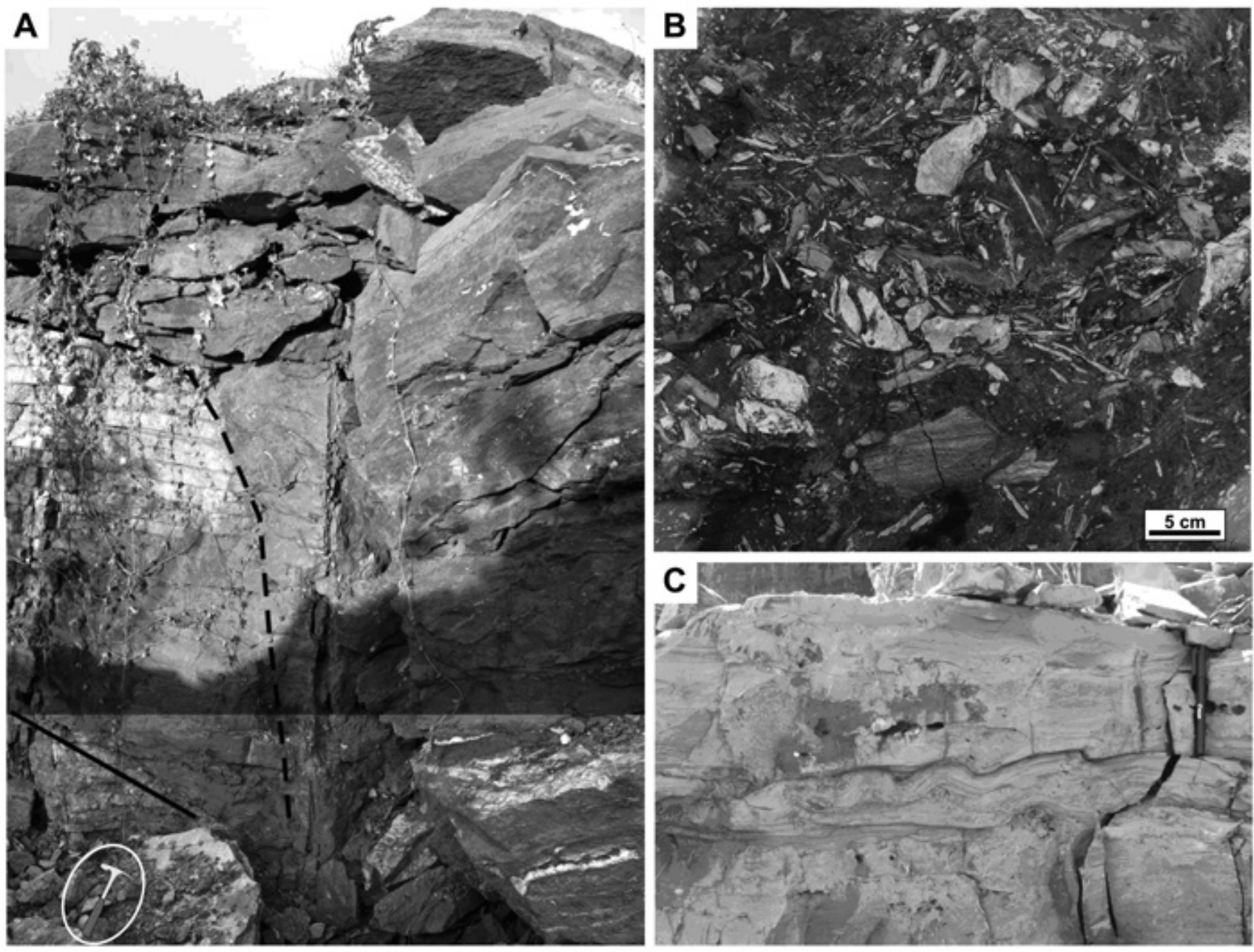

Figura 6 - Feições de deformação da Formação Guia. A) Contato (linhas pontilhadas) entre o dique neptuniano e a encaixante que são os calcários finos laminados; B) Brecha intraformacional em dique neptuniano;

C) Camada convolucionada intercalada com calcário fino laminado.

uma rampa em águas profundas devido ao acúmulo de carbonato na margem da plataforma (Coniglio \& Dix 1992, Jones \& Desrochers 1992).

ASSOCIAÇÃO DE FÁCIES As fácies sedimentares foram agrupadas em quatro associações de fácies que indicam ambientes de plataforma carbonática. Esta plataforma é dividida em rasa a moderadamente profunda influenciada por onda, mista moderadamente profunda dominada por correntes e onda, profunda supersaturada em $\mathrm{CaCO}_{3}$ e talude (Tab. 1).

Plataforma rasa a moderadamente profunda influenciada por onda - A1 Está associação de fácies é composta predominantemente por dolograinstones peloidais finos a grossos de cor rosada dispostos em camadas lateralmente contínuas por algumas dezenas de metros e com até $6 \mathrm{~m}$ de espessura (Figs. 2). A base desta associação é formada por dolograinstones com laminações plano paralelas e com truncamento de baixo ângulo produzidas, respectivamente, por alternância de suspensão e fluxos oscilatórios. Estruturas de deforma- ção sin-sedimentar como falhas normais e dobras kink ocorrem lateralmente a camadas sem deformação. A preservação de macropelóides associado às laminações com truncamentos sugere reduzida abrasão e rápida cimentação em um ambiente de águas calmas (Fig. 3C e D). A presença abundante de pelóides nesta associação é interpretada como intensa atividade microbiana que induziu a nucleação do carbonato. Estruturas produzidas por onda podem representar uma maior proximidade com a base da onda normal.

Plataforma mista moderadamente profunda dominada por corrente e onda - A2 A associação de fácies 2 é caracterizada por siltitos maciços e laminados intercalados com calcários finos cristalinos com megamarcas onduladas (Figs. 2 e 4A). As camadas de siltitos ocorrem no limite com a A 1 e forma um pacote lateralmente contínuo com espessuras variando de $20 \mathrm{~cm}$ até $1.20 \mathrm{~m}$, associadas a uma falha sin-sedimentar (Fig. 2). A espessura e a forma dos estratos neste local indicam deposição posterior ao deslocamento que gerou uma paleodepressão e, portanto um maior espaço para acumulação. Sobre 
estes estratos surgem calcários finos cristalinos com até $10 \%$ de terrígenos, que apresentam acamamento de megamarca ondulada com continuidade lateral de algumas dezenas de metros e espessura de 2,5m. Nestes calcários ocorrem megamarcas associadas com marcas onduladas que sugere intervalos de retrabalhamento por fluxos oscilatórios Em direção ao topo desta associação, camadas de $30 \mathrm{~cm}$ de siltitos se intercalam de forma cíclica com os calcários formando uma sucessão granocrescente de $\sim 3 \mathrm{~m}$ de espessura (Fig. 2). Acamamentos de megamarcas com muddrapes ocorrem lateralmente e logo acima estes ciclos representam rápida mudança na energia de fluxo. Fácies dominadas por calcário com megamarcas e lamitos organizados em sucessões granocrescentes e a abundância de terrígenos sugere uma zona de deposição influenciada por ondas e com influxo de terrígenos de águas moderadamente profundas.

Plataforma profunda supersaturada em $\mathrm{CaCO}_{3} \mathrm{com}$ fornecimento esporádico de terrígenos - A3 ${ }^{3}$ Esta associação é caracterizada por uma sucessão lateralmente contínua e com $6 \mathrm{~m}$ de espessura de camadas tabulares de calcários finos cristalinos com topo ondulado intercalados com folhelhos betuminosos (Figs. 2 e 4B). Diques neptunianos, preenchidos por brechas intraformacionais, e camadas deformadas entre camadas sem deformação são comuns nesta associação. As camadas de calcários são compostas por cristais de calcita (pseudomorfos de aragonita) centimétricos que ocorrem isolados ou conectados, estes são cobertos por laminações onduladas de micrito parcialmente dolomitizado (Figs 4C-D e 5B). Cristais desconectados são mais comuns na base da associação enquanto no topo eles se tornam mais abundantes e conectados. Laminações plano paralelas e onduladas comumente ocorrem entre e sobre os cristais e são respectivamente produtos de sedimentação em ambiente de águas calmas esporadicamente modificado pela ação de fluxos oscilatórios. Intercalações de pelito e carbonato que formam laminações convexas entre os cristais no topo da sucessão sugerem deposição provavelmente de forma simultânea, ou antes, da formação dos cristais. A abundância de cristais é resultado do aumento da alcalinidade, mudanças na circulação e temperatura oceânica e no $\mathrm{CO}_{2}$ atmosférico e, principalmente, a baixa taxa de sedimentação (Sumner 2002). No topo da associação camadas mais espessas de folhelhos betuminosos se intercalam com os calcários finos de forma cíclica (Fig. 4B). A presença de marcas onduladas no topo das camadas sugere influencia de fluxos oscilatórios que são comuns em águas rasas, porém a ocorrência de cristais nestas camadas é um forte indicio de águas profundas, geradas durante um evento de supersaturação em $\mathrm{CaCO}_{3}$. Diques neptunianos, sem feições de exposição subaérea ou de carstes, se formaram a partir do fraturamento e dilatação dos calcários da Formação Guia. A presença de diques neptunianos associados a camadas deformadas isoladas sugerem que abalos sísmicos possam ter afetado a plataforma carbonática (Winterer \& Sarti 1994, Obermeier 1996, Montenat et al. 2007).
Talude - A4 Calcários com estruturas de escorregamento (slump) e brechas intraformacionais (formando camadas métricas) que ocorrem discordantemente sobre os outros depósitos carbonáticos caracterizam esta associação (Fig. 2). Os depósitos com estruturas de slump, camadas deformadas e fraturadas apresentam uma distribuição mais ampla que as restritas brechas intraformacionais que ocorrem localmente próxima ao contato com a Formação Mirassol d'Oeste. As brechas são produtos de fragmentação e fraturamento ocasionado durante o deslocamento vertical de massas parcialmente litificadas sobre rochas calcárias e dolomíticas. Falhas normais sin-sedimentares, camadas deformadas da Formação Guia, blocos e camadas interrompidas, encontradas junto às estruturas de escorregamento e dobras convolutas, indicam movimentos verticais de massas sedimentares associados com instabilidade gravitacional em uma rampa submarina profunda. Esta instabilidade poderia ser gerada pelo acúmulo de carbonato relacionado a uma produção de sedimentos que excederia a taxa de aumento relativo do mar (Jones \& Desrochers 1992).

EVOLUÇÃO PALEOAMBIENTAL Os depósitos da região de Tangará da Serra consistem de parte do registro de uma margem de plataforma carbonática formada em águas quentes e profundas na margem SW do Cráton Amazonas durante o final do Neoproterozóico (Fig. 7). A deposição de dolomitos foi, a princípio, a primeira manifestação sedimentar nesta porção do cráton, pois o contato basal não aflora, como ocorre na sucessão de Mirassol d'Oeste. Estes dolomitos são caracterizados pela presença de pelóides e macropelóides que sugere, respectivamente, atividade biológica e rápida cimentação dolomítica em um ambiente de águas calmas. Falhas normais e dobras kink ocorrem lateralmente a camadas não deformadas de dolomitos e sugerem deformação durante a deposição. Não há evidências de exposição subaérea sobre estes dolomitos, porém tais feições podem ter sido erodidas pela ação de correntes durante a transgressão marinha pós-glacial (Fig. 7). O evento transgressivo é registrado pela deposição de siltes ricos em ferro, acima dos dolomitos, em águas profundas anóxicas onde os carbonatos poderiam estar parcialmente dissolvidos. Lateralmente, os siltes carbonatos terrígenos, migraram na forma de megamarcas onduladas sob ação de ondas em ambiente moderadamente raso de plataforma (Fig. 7). A rápida subida do nível do mar (clímax do evento transgressivo) propiciou o aumento da alcalinidade que associada à redução da taxa de sedimentação e energia em águas supersaturadas em $\mathrm{CaCO}_{3}$ tornou possível a deposição de lama carbonática e precipitados arborescentes de aragonita (Fig. 7). A contribuição de terrígenos pode ser devido a áreas fontes soerguidas relacionadas a colisão de crátons (Amazonas e Rio de La Plata) ou áreas expostas pós-glaciação. Diques neptunianos e camadas deformadas entre camadas sem deformação que ocorrem nas intercalações de calcário e folhelho são interpretados como produtos de abalos sísmicos que 

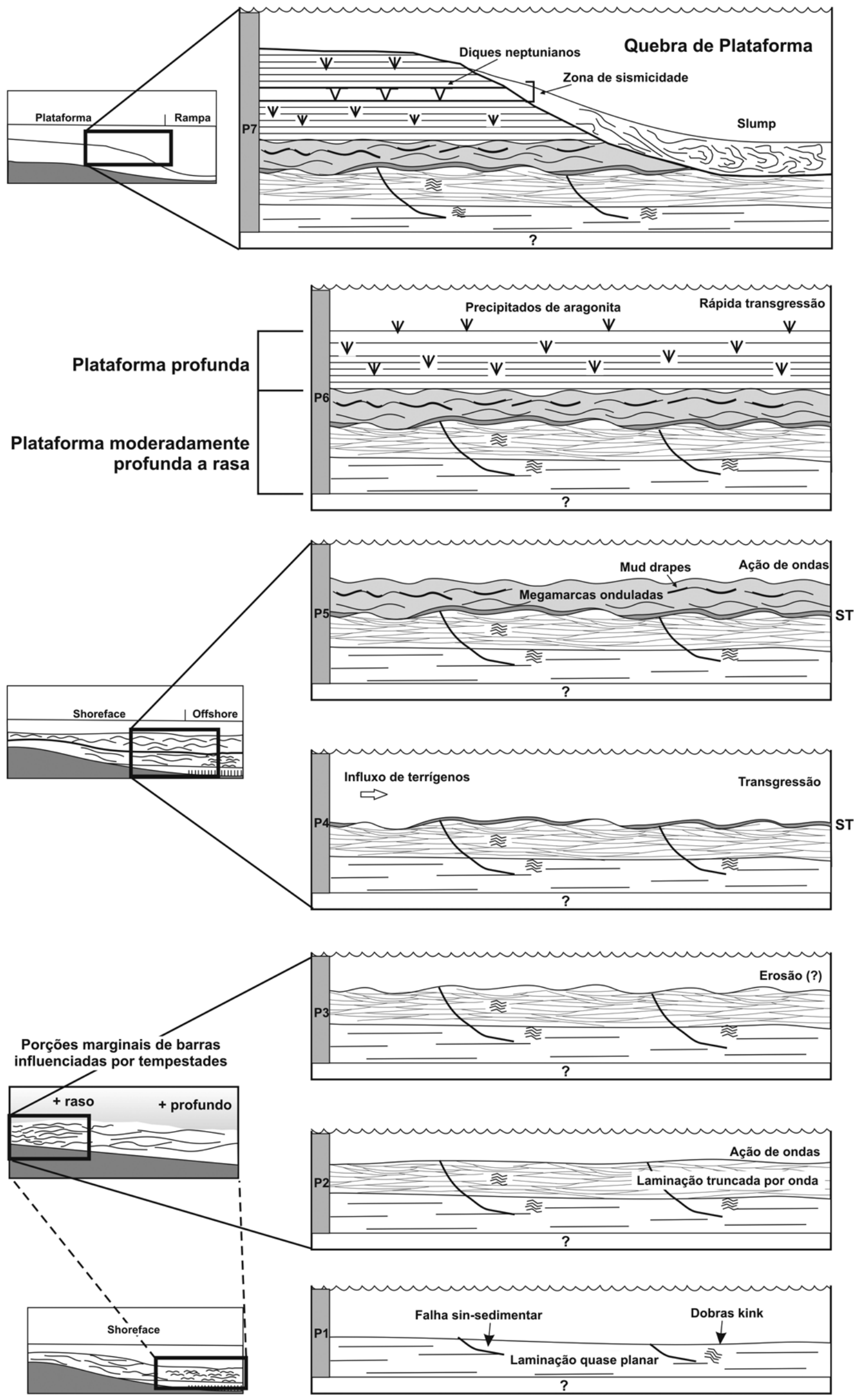

Figura 7 - Modelo evolutivo da plataforma carbonática de Tangará da Serra. Símbolos: $P=$ profundidade; $S T=$ superficie transgressiva. 
afetaram a Plataforma Araras no Ediacarano. Estruturas de escorregamento e de deformação sin-sedimentar indicam movimentos gravitacionais descendentes associados à declividade de rampa e ao acúmulo excessivo de carbonato em águas profundas (Fig. 7). O transporte de sedimentos em direção as regiões mais baixas promoveu a progradação e expansão da margem da plataforma (Jones \& Desrochers 1992).

CONCLUSÕES A sucessão de fácies de capa carbonática descrita em Tangará da Serra representada por dolomitos rosados, estruturas truncadas por onda e principalmente leques de cristais de aragonita com valores isotópicos de carbono negativo, dentro de um arcabouço transgressivo, apesar de apresentarem algumas fácies distintas da sucessão descrita na mina Terconi em Mirassol d'Oeste (Nogueira e Riccomini 2007), sugerem que são correspondentes a mesma sucessão de capa carbonática pós-glaciação Puga.

Em Tangará da Serra afloram a porção mais superior da capa dolomítica (Formação Mirassol d'Oeste) e a parte inferior da capa calcária (Formação Guia inferior) da Plataforma Araras. A capa dolomítica é caracterizada por dolograinstones peloidais depositados em águas rasas a relativamente profundas. O contato plano a irregular entre as capas dolomítica e calcária é uma superfície transgressiva. Sobre este contato a capa calcária é representada por siltitos e calcários terrígenos com acamamentos de megamarcas onduladas depositados em águas moderadamente profundas influenciada por onda. Calcários com le- ques de cristais de calcita (pseudomorfos de aragonita) e folhelhos betuminosos indicam um evento de supersaturação em $\mathrm{CaCO}_{3}$ associado à transgressão marinha. Camadas deformadas entre camadas sem deformação e diques neptunianos indicam que ocorreu um evento sísmico durante a deposição dos calcários Guia. Depósitos calcários com estruturas de escorregamento e deformações sin-sedimentares são evidências de acúmulo excessivo de carbonato que resultou em deslizamentos gravitacionais. A sucessão estudada de Tangará da Serra amplia a interpretação de capas carbonáticas para o sul do Cráton Amazônico e corrobora com a presença de uma extensa plataforma carbonática formada durante eventos transgressivos pósglaciação Marinoana.

Agradecimentos Aos Profs. Dr. C. Riccomini e Dr. W. Truckenbrodt pelas excelentes sugestões que contribuíram para melhorar o presente texto, a mina Calcário Tangará pelo apoio logístico e ao engenheiro de mina Sávio dos Santos por sua colaboração. A FAPEAM pelo financiamento da bolsa de mestrado. Ao projeto FAPESP coordenado pelo Prof. C. Riccomini pelo apoio financeiro na primeira etapa de campo. Ao projeto Hidrocarbonetos em carbonatos pré-cambrianos do Sul do Cráton Amazônico: Um estudo inicial dos sistemas petrolíferos pós-snowball Earth (processo 485902/20079). Edital MCT/CNPq 15/2007 - Universal, pelo apoio financeiro nas outras etapas de campo. Finalmente aos alunos e geólogos do Grupo de Análise de Bacias Sedimentares da Amazônia - GSED da UFPA.

\section{Referências}

Adams A.E., MacKenzie W.S., Guilford C. (eds.) 1984. Atlas of sedimentary rocks under the microscope. Longman, Harlow, 140p.

Aigner T. 1985. Storm Depositional Systems. Lecture Notes in Earth Sciences, Berlim, Springer-Verlag, 174p.

Allen P.A. \& Hoffman P.F. 2005. Extreme winds and waves in the aftermath of a Neoproterozoic glaciation. Nature, 433:123-127.

Almeida F.F.M. \& Mantovani M.S.M. 1975. Geologia e geocronologia do Granito de São Vicente, Mato Grosso. An. Acad. Bras. Ciênc., 47:451-458.

Alvarenga C.J.S., Santos R.V., Dantas E.L. 2004. C-O-Sr isotopic stratigraphy of cap carbonates overlying Marinoan-age glacial diamictites in the Paraguay Belt, Brazil. Precambrian Research, 131:1-21.

Alvarenga C.J.S., Figueiredo M.F., Babinski M., Pinho F.E.C. 2007. Glacial diamictites of Serra Azul Formation (Ediacaran, Paraguay Belt): Evidence of the Gaskiers glacial event in Brazil. Jour. South Americ. Earth Scien., 23:236-241.

Alvarenga C.J.S., Dardenne M.A., Santos R.V., Brod E.R., Gioia S.M.C.L., Sial A.N., Dantas E.L., Ferreira V.P. 2008. Isotope stratigraphy of Neoproterozoic cap carbonates in the Araras Group, Brazil. Gondwana Research, 13:469-479.
Amaral G., Cordani U.G., Kawashita K., Reynolds J.H. 1966. Potassium-argon dates of basaltic from southern Brazil. Geochimica et Cosmochimica Acta, 30:159189.

Arnott R.W.C., Hein F.J., Pemberton S.G. 1995. Influence of the ancestral Sweetgrass Arch on sedimentation of the Lower Cretaceous Bootlegger Member, north-central Montana. Jour. Sedimentary Research, 65:222-234.

Bowring S., Myrow P., Landing E., Ramezani J., Grotzinger J. 2003. Geochronological constraintson terminal Neoproterozoic events and the rise of metazoans. Geophysical Research Abstracts, 5:13219.

Clough J.G.\& Goldhammer R.K. 2000. Evolution of the Neoproterozoic Katakturuk Dolomite Ramp Complex, northeastern Brooks Range, Alaska. In: Grotzinger J.P. \& James N.P. (eds.) Carbonate Sedimentation and Diagenesis in the Evolving Precambrian World. Society for Sedimentary Geology, Tulsa, 67, SEPM Special Publication, p. 209-241.

Coleman J.M. \& Prior D.B. 1988. Mass wasting on continental margins. Ann. Rev. Earth Planet. Sci., 16:101119.

Coniglio M. \& Dix G.R. 1992. Carbonate Slopes. In: Walker R.G. \& James N.P. (eds.) Facies Models - Response to Sea Level Change. Ontario, Geological Association of 
Canadá, p. 349-373.

Corsetti F.A., Lorentz N.J., Pruss S.B. 2004. Formerly-Aragonite Seafloor Fans from Neoproterozoic Strata, Death Valley and Southeastern Idaho, United States: Implications for "Cap Carbonate" Formation and Snowball Earth. In: Jenkins G., McMenamin M., Sohl L. (eds.) The Extreme Proterozoic: Geology, Geochemistry, and Climate. American Geophysical Union Geophysical Monograph Series, 146, Washington, DC, p. 33-44.

De Raaf J.F.M., Boersma J.R., Van Gelder A. 1977. Wave generated structures and sequences from a shallow marine succession. Lower Carboniferous, County Cork, Ireland. Sedimentology, 4:1-52.

Fairchild I.J. \& Hambrey M.J. 1984. The Vendian of NE Spitsbergen: petrogenesis of a dolomite/tillite association. Precambrian Research, 26:111-167.

Faulkner T.J. 1988. The Shipway Limestone of Gower: sedimentation on a storm-dominated early Carboniferous ramp. Geol. J., 23:85-100.

Fike D.A., Grotzinger J.P., Pratt L.M., Summons R.E. 2006. Oxidation of the Ediacaran Ocean. Nature, 444:744747.

Font E., Nédélec A., Trindade R.I.F., Macouin M., Charrière A. 2006. Chemostratigraphy of the Neoproterozoic Mirassol d'Oeste cap dolostones (Mato Grosso, Brazil): An alternative model for Marinoan cap dolostone formation. Earth and Planetary Science Letters, 250:89-103

Grey K. 2005. Ediacaran palynology of Australia. Memoir of the Association of Australasian Palaeontologists 31:1-439.

Grotzinger J.P.S. \& Knoll A.H. 1995. Anomalous carbonate precipitates: is the Precambrian the key to the Permian? Palaios, 10:578-596.

Halverson G.P., Maloof A.C., Hoffman P.F. 2004. The Marinoan glaciation (Neoproterozoic) in northeast Svalbard. Basin Research, 16:297-324.

Halverson G.P., Hoffman P.F., Schrag D.P., Maloof A.C., Rice A.H.N. 2005. Toward a Neoproterozoic composite carbon-isotope record. GSA Bulletin, 117:1181-1207.

Hidalgo R.L.L, Petri S., Nogueira A.C.R. 2008. Post-Sturtian and Early Ediacaran microfossils of carbonates sequences in Brazil. In: IAS Meeting of Sedimentology, $26^{\text {th }}$, Bochum, Resumo digital.

Hoffman P.F. \& Schrag D.P. 2002. The Snowball Earth hypothesis: testing the limits of global changes. Terra Nova, 14:129-155.

Hoffman P.F., Kaufman A.J., Halverson G.P., Schrag D.P. 1998a. A Neoproterozoic Snowball Earth. Science, 281:1342-1346.

Hoffman P.F., Kaufman A.J., Halverson G.P., Schrag D.P. 1998b. Comings and goings of global glaciations on a neoproterozoic tropical platform in Namibia. GSA Today, 8:1-9.

Hyde W.T., Crowley T.J., Baum S.K., Peltier W.R. 2000. Neoproterozoic "snowball Earth" simulations with a coupled climate/ice-sheet model. Nature, 405:425-429.

James N.P., Narbonne G.M., Kyser T.K. 2001. Late Neoproterozoic cap carbonates: Mackenzie Mountains, northwestern Canada: precipitation and global glacial meltdown. Can. J. Earth Sci., 38:1229-1262.
Jones B. \& Desrochers A. 1992. Shallow platform carbonates. In: Walker R.G. \& James N.P. (eds.) Facies Models -Response to Sea Level Change. Ontario, Geological Association of Canada, pp. 277-301.

Kennedy M.J. 1996. Stratigraphy, sedimentology, and isotopic geochemistry of Australian Neoproterozoic postglacial cap dolostones: deglaciation, $\delta^{13} \mathrm{C}$ excursions, and carbonate precipitation. Journ. Sedim. Research, 66:1050-1064.

Kennedy M.J., Christie-Blick N., Sohl L.E. 2001. Are Proterozoic cap carbonates and isotopic excursions a record of gas hydrate destabilization following Earth's coldest intervals? Geology, 29:443-446.

Kerans C. \& Tinker S.W. 1997. Sequence Stratigraphy and characterization of carbonate reservoirs. Society for Sedimentary Geology, Tulsa, 40, SEPM Special Publication, 130p.

Kirschvink J.L. 1992. Late Proterozoic low latitude glaciation: the snowball earth. In: Schopf J.W. \& Klein C. (eds.) The Proterozoic Biosphere: A Multidisciplinary Study. Cambridge, Cambridge University Press, p. 5152.

Knoll A.H. \& Walter M.R. 1992. Latest Proterozoic stratigraphy and Earth history. Nature, 356:673-678.

Lorentz N.J., Corsetti F.A., Link P.K. 2004. Seafloor precipitates and C-isotope stratigraphy from the Neoproterozoic Scout Mountain Member of the Pocatello Formation, southeast Idaho: implications for Neoproterozoic earth system behavior. Precambrian Res., 130:57-70.

Lowe D.R. 1975. Water escape structures in coarse-grained sediments. Sedimentology, 22:157-204.

Mills P.C. 1983. Genesis and diagnostic value of soft-sediment deformation structures - a review. Sedim. Geol., 35:83-104.

Misi A., Kaufman A. J., Veizer J., Powis K., Azmy K., Boggianni P.C., Gaucher C., Teixeira J.B.G., Sanches A.L., Iyer S.S.S. 2007. Chemostratigraphic correlation of Neoproterozoic successions in South America. Chem. Geol., 237:143-167.

Moczydlowska M. 2008. New records of late Ediacaran microbiota from Poland. Precambrian Research, 167:7192.

Montenat C., Barrier P., D’Estevou P.O., Hibsch C. 2007. Seismites: An attempt at critical analysis and classification. Sedimentary Geology, 196:5-30.

Myrow P.M. \& Kaufman A.J. 1999. A newly discovered cap carbonate above Varanger-age glacial deposits in Newfoundland. Can. J. Sed. Res., 69:784-793.

Mulder T. \& Cochonat P. 1996. Classification of offshore mass movements. J. Sed. Res., 66:43-57.

Narbonne G.M., Kaufman A.J., Knoll A.H. 1994. Integrated chemostratigraphy and biostraigrahy of the upper Windermere Supergroup (Neoproterozoic), northwestern Canada: Implications for Neoproterozoic correlations and the early evolution of animals. GSA Bulletin, 106:1281-1292.

Nogueira A.C.R. 2003. A plataforma carbonática Araras no sudeste do Cráton Amazônico, Mato Grosso: Estratigrafia, contexto paleoambiental e correlação com os eventos glaciais do Neoproterozóico. Tese de Doutoramento, 
Programa de Pós-Graduação em Geologia Sedimentar, Universidade de São Paulo, 173p.

Nogueira A.C.R. \& Riccomini C. 2006. O Grupo Araras (Neoproterozóico) na parte norte da Faixa Paraguai e sul do Cráton Amazônico, Brasil. Rev. Bras. Geoc, 36:623640.

Nogueira A.C.R., Riccomini C., Sial A.N., Moura C.A.V., Fairchild T.R. 2003. Soft-sediment deformation at the base of the Neoproterozoic Puga cap carbonate (southwestern Amazon Craton, Brazil): Confirmation of rapid icehouse to greenhouse transition in snowball Earth. Geology, 31:613-616.

Nogueira A.C.R., Riccomini C., Sial A.N., Moura C.A.V., Trindade R.I.F., Fairchild T.R. 2007. Carbon and Strontium isotope fluctuations and paleoceanographic changes in the late Neoproterozoic Araras carbonate platform, southern Amazon Craton, Brazil. Chemical Geology, 237:168-190.

Obermeier S.F. 1996. Use of liquefaction-induced features for paleoseismic analysis-An overview of how seismic liquefaction features can be distinguished from other features and how their regional distribution and properties of source sediment can be used to infer the location and strength of Holocene paleo-earthquakes. Engineering Geology, 44:1-76.

Santos R.V., de Alvarenga C.J.S., Dardenne M.A., Sial A.N., Ferreira V.P. 2000. Carbon and oxygen isotope profiles across Meso-Neoproterozoic limestones from central Brazil: Bambuí and Paranoá groups. Precambrian Res., 104:107-122.

Soares J.L. 2008. Estratigrafia e paleoambiente da capa carbonática Neoproterozóica da região de Tangará da Serra, Mato Grosso. Dissertação de Mestrado, Programa de Pós-Graduação em Geologia Regional, Universidade Federal do Amazonas, 83p.

Sumner D.Y. 2002. Decimeter-thick encrustations of calcite and aragonite on the sea-floor and implications for Neoarchaean and Neoproterozoic ocean chemistry. In:
Altermann W. \& Corcoran P.L. (eds.) Precambrian Sedimentary Environments: a Modern Approach to Ancient Depositional Systems. International Association of Sedimentologists, 33, Special Publication, p. 107-120.

Trindade R.I.F., Font E., D’Agrella-Filho M.S., Nogueira A.C.R., Riccomini C. 2003. Low-latitude and multiple geomagnetic reversals in the Neoproterozoic Puga cap carbonate, Amazon craton. Terra Nova, 15:441-446.

Tucker M.E. 1992. Sedimentary Petrology: an introduction to the origin of sedimentary rocks. Blackwell Scientific Publications, $2^{\circ}$ ed., 260p.

Valente C.R., Lacerda Filho J.V., Rizzotto G.J., Bahia R.B.C, Quadros M.L.E.S., Leite S.R., Lopes R.C., Oliveira I.W.B., Sachs L.L.B., Silva V.A., Batista I.H. 2004. Folha SD.21 - Cuiabá. Mapa na escala de 1: 1.000.000. In: Schobbenhaus C., Gonçalves J.H., Santos J.O.S., Abram M.B., Leão Neto R., Matos G.M.M., Vidotti R.M., Ramos M.A.B., Jesus J.D.A. (eds.). Carta Geológica do Brasil ao Milionésimo, Sistema de Informações Geográficas - SIG., Programa Geologia do Brasil. CPRM, Brasília.

Visher G.S. \& Cunningham R.D. 1981. Convolute laminations - a theoretical analysis: example of a Pennsylvanian Sandstone. Sedim. Geol., 28:175-188.

Walker R.G. 1992. Facies, facies models and modern stratigrahic concepts. In: Walker R.G. \& James N.P. (eds.) Facies Models - Response to Sea Level Change. Ontario, Geological Association of Canada, p. 1-14.

Winterer E.L. \& Sarti M. 1994. Neptunian dykes and associated features in southern Spain: mechanics of formation and tectonic implications. Sedimentology, 41:11091132.

Manuscrito ID 11152

Submetido em 22 de abril de 2008

Aceito em 16 de dezembro de 2008 Sistema eletrônico de submissão 